\title{
Spasticity, CTCAE
}

National Cancer Institute

\section{Source}

National Cancer Institute. Spasticity, CT CAE. NCI Thesaurus. Code C143854.

A disorder characterized by increased involuntary muscle tone that affects the regions

interfering with voluntary movement. It results in gait, movement, and speech

disturbances. 